\title{
Cultura cidadã no Brasil: aproximações entre educação fiscal e gestão social
}

Gestão Social e Educação Fiscal são temas recentes que problematizam a questão da cidadania como instrumento regulador da relação Estado e sociedade, a partir de um processo de formação cultural, voltado à conscientização dos cidadãos. Assim sendo, o objetivo deste artigo é discutir a aproximação dos temas educação fiscal e gestão social, baseado na perspectiva de construção da cultura cidadã no Brasil. Para isso, realizou-se uma análise crítica em aportes teóricos de trabalhos publicados a respeito dos temas, na forma de uma revisão narrativa, com o intuito de melhor apresentar as discussões sobre as matérias. Inicialmente, apresentase um resgate histórico do processo de formação do Estado brasileiro, com maior enfoque para as questões político-sociais. Em seguida, aborda-se a influência internacional na construção da cultura cidadã do país, os principais conceitos de cultura política, social e cidadã, além das transformações sociais e populacionais ocorridas no Brasil, desde a colonização portuguesa. Após, expõe-se as principais aproximações e características comuns que tornam a educação fiscal e a gestão social, políticas com forte poder de transformação da sociedade, enfatizando que o somatório da educação fiscal com a gestão social alimenta a esperança por dias melhores, já que possuem a participação popular (cidadão) como a principal estratégia de mudança social no país.

Palavras-chave: Educação fiscal; Gestão social; Política pública; Cidadania.

\section{Citizen culture in Brazil: approaches between fiscal education and social management}

\begin{abstract}
Social Management and Tax Education are recent themes that problematize the issue of citizenship as an instrument that regulates the relationship between State and society, based on a process of cultural formation, aimed at raising citizens' awareness. Therefore, the objective of this article is to discuss the approximation of the themes of tax education and social management, based on the perspective of building citizen culture in Brazil. For this, a critical analysis was carried out on theoretical contributions of published works on the themes, in the form of a narrative review, in order to better present the discussions on the subjects. Initially, there is a historical recovery of the formation process of the Brazilian State, with a greater focus on political and social issues. Then, it addresses the international influence in the construction of the country's citizen culture, the main concepts of political, social and citizen culture, in addition to the social and population changes that have occurred in Brazil since Portuguese colonization. Afterwards, it exposes the main common approaches and characteristics that make tax education and social management policies with a strong power to transform society, emphasizing that the sum of tax education and social management fuels hope for better days, since have popular participation (citizen) as the main social change strategy in the country.
\end{abstract}

Keywords: Tax education; Social management; Public policy; Citizenship.

Topic: Gestão Pública

Reviewed anonymously in the process of blind peer.
Received: 07/01/2021

Approved: 22/03/2021

Rodrigo José Lima Almeida (iD

Universidade Federal do Recôncavo da Bahia, Brasil

http://lattes.cnpq.br/6884388955579724

http://orcid.org/0000-0003-2084-1539

digoanalise@gmail.com

Isnaya Almeida Brandão Lima (iD)

Instituto Tocantinense Presidente Antônio Carlos, Brasil

http://lattes.cnpq.br/5345666499675287

http://orcid.org/0000-0002-5725-7195

nayabrandao@gmail.com

Referencing this:

ALMEIDA, R. J. L.; LIMA, I. A. B.. Cultura cidadã no Brasil: aproximações entre educação fiscal e gestão social. Revista Brasileira de Administração Científica, v.12, n.1, p.246-255, 2021. DOI: http://doi.org/10.6008/CBPC2179-684X.2021.001.0020 


\section{INTRODUÇÃO}

Nos últimos anos, os temas gestão social e educação fiscal têm sido explorados para acentuar a importância da cidadania e das questões sociais na relação estado-sociedade, sobretudo no processo de implementação de políticas públicas.

Na Europa, Oceania e principalmente América do Norte, já existe uma acentuada maturidade cultural a respeito dos temas, de modo que países como Canadá, Estados Unidos, Dinamarca, Suécia e Austrália conseguem obter resultados expressivos em programas desenvolvidos para o pleno exercício da cidadania (PEREIRA et al., 2016).

No Brasil, a discussão em relação à educação fiscal ainda é incipiente. O desconhecimento da sociedade a respeito de temas elementares, como controle social, aumenta a necessidade de orientação desses indivíduos (GRZYBOVSKI et al., 2006). A Gestão Social, por sua vez, encontra-se em estado de progresso, sendo construída com base na gestão democrática e participativa (CANÇADO et al., 2011).

Neste artigo, recorre-se a literatura para discutir os temas educação fiscal e gestão social, suas aproximações e caminhos para o fomento à cultura cidadã no Brasil. Além disso, faz-se um resgate histórico da influência internacional no processo de surgimento da cultura cidadã brasileira. Ao final, evidencia-se a aproximação e as características comuns aos temas que os tornam como umas das principais políticas públicas de transformação social no país.

Por uma questão didática os temas serão desenvolvidos de forma dissociada, sendo correlacionados quando existir convergência do conteúdo. O artigo divide-se em três partes, começando com esta introdução, seguida da contextualização histórica da gestão social e educação fiscal. Na seção seguinte expõe-se como se construiu a cultura cidadã brasileira e a influência internacional nesse processo; e na terceira, os aportes teóricos para a gestão social e educação fiscal como política pública de transformação social no Brasil. Por fim, apresentam-se as considerações finais.

\section{METODOLOGIA}

Trata-se de um estudo qualitativo que descreve e discute os temas Educação Fiscal e Gestão Social, sob o ponto de vista teórico e contextual, na forma de uma revisão narrativa. Segundo Rother (2007), este tipo de trabalho é constituído de uma análise crítica pessoal do autor, a partir de estudos publicados em diversos periódicos. Essa categoria de trabalho tem papel decisivo no modelo de educação continuada, uma vez que são publicações amplas, que descrevem e discutem o desenvolvimento de um determinado tema.

Para uma melhor identificação dos temas, utilizou-se de alguns livros e de trabalhos pesquisados em banco de dados de periódicos eletrônicos, como: SciELO, CAPES e Dialnet. Adotou-se como principais descritores: Educação Fiscal e Gestão Social. Para refinar a busca, palavras sinônimas, como: controle social, cultura cidadã, cidadania, gestão participativa foram empregadas com o intuito de se coletar o máximo de referências possíveis.

A partir da leitura dos livros e dos artigos encontrados, selecionaram-se os que seriam incluídos na 
pesquisa, sendo adotado como critério de inclusão: ter relação direta com o objetivo central deste trabalho.

\section{DISCUSSÃO TEÓRICA}

\section{Breve contexto histórico}

A origem do Estado brasileiro é marcada por uma economia agrícola mercantil, com traços de escravismo, alicerçada por um Estado oligárquico e patrimonial. Até chegar ao modelo vigente, o país passou por profundas transformações, com destaque para os fatores econômicos, sociais e políticos. Da oligarquia patrimonial transitou-se pela burocracia até o gerencialismo, a sociedade capitalista substituiu a senhorial, a democracia sobrepôs-se ao autoritarismo, enquanto que a economia de subsistência difere muito do que se evidência atualmente com natureza pós-industrial (BRESSER-PEREIRA, 2001).

Após 1930, o Brasil ganhou uma vertente administrativa stricto sensu que simbolicamente proporcionou uma ruptura dos mecanismos oligárquicos, passando o país a utilizar os princípios weberianos. A partir de 1964, já com princípios desenvolvimentistas, ocorreu o início do processo de expansão do Estado na vida econômica e social, o que impulsionou, no final do século XX, a adoção do modelo econômico de bem-estar social (BRASIL et al., 1998).

O Welfare Stare no Brasil e em toda região latino-americana reabriu espaços para discussões integradas de economia e políticas sociais, que eram tratadas de forma dissociadas pelas correntes de forte viés quantitativo, a formalista e a abstrata. Esse novo cenário é marcado pela solidificação das bases materiais do progresso social, em especial pela promoção do crescimento econômico a partir de políticas sociais (DRAIBE et al., 2011).

Somado a isso, o país adotou o conceito "neodesenvolvimentista" como estratégia para os rumos da política social. Por se tratar de um paradigma global, seus fundamentos ocorrem de forma bilateral e com forte influência internacional. Desde então, tendo a ética capitalista e o neoliberalismo como pressupostos, as políticas sociais inseriram-se em contextos competitivos e que, por natureza própria, possuem regras e interesses antissociais (PEREIRA, 2012).

A partir do século XX, as políticas públicas incorporaram-se às estruturas do Estado, insurgindo uma atividade política com decisão social. Nesse contexto de transformação político-social, o Estado Moderno passa a ser um agente transformador da vida social, moldando a sua atuação para o desenvolvimento da sociedade (DERANI, 2004).

No Brasil, esse contexto de modernização do Estado é respaldado pela Constituição Federal de 1988, que dentro de uma perspectiva de quebra de paradigmas, desconsiderou alguns princípios até então vigentes, como centralização, rigidez e hierarquia. A transição desse período de gestão burocrática para gerencial fomentou a mudança de perspectiva do Estado, que a partir de então foi instigado a vislumbrar de outra forma as necessidades da população (BRASIL et al., 1998).

Em decorrência desse processo de amadurecimento político e institucional, a sociedade brasileira, por meio de algumas experiências, aumentou a sua participação político-social, efetivando práticas como o 
controle social e a promoção do accountability (SCHOMMER et al., 2012).

Emerge-se, a partir desse novo contexto, dois novos conceitos: a educação fiscal, como atributo capaz de elevar os resultados das políticas e programas direcionados ao bem comum a partir do aumento do nível de compreensão e participação do cidadão (BORGES et al., 2014), e a Gestão Social, que está sustentada no conceito de cidadania deliberativa, que tem como essência a inclusão, pluralismo, participação, igualdade e autonomia nos processos de legitimação das decisões políticas, o que direciona as discussões para as relações entre os pares ou em suas combinações sociedade-Estado e sociedade-mercado (TENÓRIO, 2005).

Partindo desta breve contextualização que evidencia algumas transformações políticas-sociais do Brasil, será apresentada a influência internacional na construção da cultura cidadã brasileira em sua perspectiva conceitual.

\section{Cultura Cidadã e a Influência Internacional na Cidadania Brasileira}

Só há cultura em homens e mulheres concretos que pertençam a um povo e em um determinado território. Assim, somente pode-se conceituar cultura quando existir interação dialética entre os indivíduos, a partir de uma dimensão social (VANNUCCHI, 2006). Nesse aspecto, o fenômeno cultural a ser discutido nesta seção leva em consideração os fatores culturais a partir de perspectivas sociais e políticas.

Assim, a conceituação de cultura política torna-se indispensável, na medida em que a cultura cidadã brasileira recebe influência de diversos países, modificando hábitos e constituindo conjuntos de normas, valores e outros fenômenos políticos. Esse processo cultural-político é caracterizado por Motta (1996) como um "conjunto de normas, valores, atitudes, crenças, linguagens e imaginário, partilhados por determinado grupo, e tendo como objeto fenômenos políticos".

Por outro lado, o conceito de cultura cidadã é mais recente. Segundo Echeverri et al. (2016), o conceito tem origem na Colômbia, em meados da década de 1990, sendo Antanas Mockus, filósofo e matemático, principal percussor do tema, que definiu a cultura cidadã como um conjunto harmônico formado por lei, moral e cultura.

A teoria mockusiana ou de Mockus, como é popularmente conhecida, sobre cultura cidadã teve aplicação e avaliação em importantes cidades da América Latina, como: Bogotá, Medellín, Monterrey, Belo Horizonte, Quito, La Paz e outras. Para facilitar a sua compreensão, Mockus fez uma analogia entre o comportamento da sociedade e uma partida de futebol. $\mathrm{O}$ autor justifica que assim como na cultura cidadã, o futebol também é movido pelos elementos lei, moral e cultura, onde as normas/leis, que podem ou não ser quebradas, são definidas por um organismo que o gere e os aspectos morais e culturais estão presentes nos atores envolvidos, como: jogadores e torcedores (ECHEVERRI et al., 2016).

A figura abaixo, elaborada por Echeverri et al. (2016), apresenta a ideia do modelo de cultura cidadã proposto por Mockus et al. (2003), a partir das ideias de harmonia ou divórcio entre lei, moral e cultura que existem no comportamento político-social.

Mockus et al. (2003) informam também sobre a existência de 05 (cinco) fatores independentes que são necessários para convivência cidadã: 1 - formar a capacidade de construir acordos e cumpri-los; 2 - 
eunomia (redução da anomia); 3 - adesão às leis e as normas; 4 - promover o pluralismo; e 5 - ordem, mas com lei e superação da supervisão com acordos.

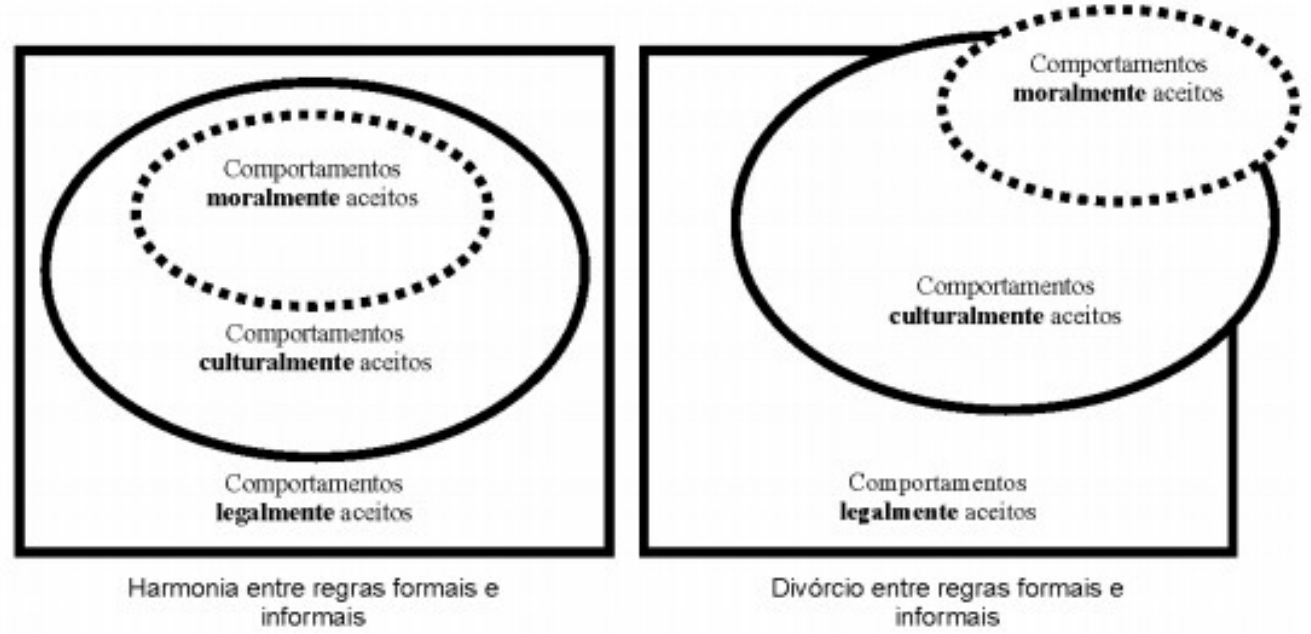

Figura 1: Modelo da cultura cidadã. Fonte: Echeverri et al. (2016).

Do ponto de vista da cultura social, Velho (1989) comenta que a construção de um processo cultural é resultado de uma vida em sociedade que tem como pressuposto relações sociais que são capazes de gerar e acumular determinados conteúdos - a cultura.

Relativamente à luz dos conceitos de cultura política, social e cidadã é que surge a cidadania no Brasil. Para Fortes et al. (2002) a década de 1990 é o período em que se inicia mais fortemente o movimento de cidadania no país, onde a sociedade passou a ocupar praças e avenidas, por meio de mobilizações, na defesa de bandeiras que retratavam aspectos sociais e políticos.

A partir desse período, o modelo de cidadania se impôs no Brasil como ideia central de reflexões das relações entre política (estado) e sociedade. A onda cidadã acenou para novas discussões em torno dos rumos do país, evidenciando questões até então pouco exploradas ou restritas ao poder estatal (FORTES et al., 2002).

Esse processo de transformação do país evidencia as influências internacionais recebidas desde a sua origem, com os efeitos da colonização portuguesa. Estima-se, ao tempo de sua descoberta, que o Brasil era habitado por 1 a 3 milhões de aborígenes, população eminentemente nativa, que sofreu forte influência europeia a partir da chegada dos portugueses e seu método de colonização baseado na economia extrativista (HUGON, 1973).

A partir do século XIX inicia-se um processo de transformação social e populacional no país, advindos dos efeitos da transição demográfica da Europa e da migração africana que o país recebia em busca de trabalho (RODRIGUES, 1945). A abertura oficial dos portos em 1808 marcou o início de um aumento significativo de estrangeiros no país (D'ÁVILA, 1956).

Nessa época, o país começava a construir a sua identidade, pensada a partir da tríade branco, índio e negro, tendo o português branco, latino e católico como figura hegemônica no processo de democracia racial (pela miscigenação). Os brancos em sua maioria eram cidadãos europeus que, seduzidos por agentes de serviços, embarcavam em busca de melhores dias para a "terra da promissão", o Brasil (OLIVEIRA, 2002). 
A cultura não é estática, estando em constante mudança em qualquer país. Os empréstimos culturais alimentam a dinamicidade cultural, podendo tudo ser adaptados aos interesses envolvidos no processo (BURKE, 1997). Para Oliven (1989), uma das principais riquezas culturais do Brasil é a sua capacidade de absorver o que vem de fora, digerindo o novo e moldando ou não a sua realidade. Carvalho (1990) exemplifica essa característica citando a utilização da filosofia Francesa do positivismo como estratégia política e militar na proclamação da república.

Apesar de todo processo histórico e influencia internacional, a questão da identidade nacional continua sendo discutida no Brasil. O debate acerca da melhor organização de nação para o país continua em evidência, sendo alimentado pela discussão do que é autêntico (nacional) e o que é moderno (estrangeiro). Existe, portanto, a necessidade de uma cultura vanguardista, capaz de produzir uma autêntica cultura para o povo brasileiro (OLIVEN, 2001).

A seguir serão ainda mais exploradas essas duas estratégias de transformação social que tem influenciado a cultura brasileira: a Educação Fiscal e a Gestão Social.

\section{Educação Fiscal e Gestão Social: Aproximações como Política Pública de Transformação Social no Brasil}

O Estado vem mudando seu comportamento ao longo dos anos, de maneira que a prática de atividades com finalidades sociais tem sido cada vez mais constante. O reflexo desse novo contexto é o processo de transformação social, capitaneado pelas políticas públicas (DERRANI, 2004).

Para Cunha et al. (2002), as políticas públicas constituem caminhos necessários para a distribuição e redistribuição de serviços sociais, a partir de desejos da sociedade. Costa (1998) acrescenta informando que a formulação das decisões que satisfazem as demandas sociais é proveniente de atores governamentais.

Assim, é a própria sociedade que constrói a realidade social. Os atores, nela presentes, possuem pontos de vista, interesses e posições que desejam transformar ou conservar. Logo, os sujeitos são capazes de modificar um determinado espaço social (BOURDIEU, 1992).

O processo de formação e transformação da política social brasileira não foi isolado, unilateral e nem autônomo. É certo que, mesmo construída de forma desconectada com o resto do mundo, o país não esteve imune às forças internacionais, sobretudo, no que tange a ideologia neoliberal, iniciada no final dos anos 1970 (PEREIRA, 2012).

Segundo Sader (2004), o Brasil, capitaneado pela onda (neo)liberal de 1990, teve o primeiro contato com o conceito de gestão social. Para Tenório (1998), esse conceito serviu para despertar os sistemasgoverno sobre a relevância das questões sociais, no que tange à prática de políticas públicas.

Resumidamente, define-se Gestão Social como um processo decisório que é exercido por atores sociais, de forma participativa e com o uso diálogo como ferramenta motriz. Trata-se, portanto, de um paradigma orientado para a participação e entendimento mútuo entre os sujeitos, sempre de forma argumentativa e nunca impositiva (TENÓRIO, 1998).

O propósito da Gestão Social é o interesse coletivo de natureza pública, tendo como foco à racionalidade, o processo decisório, a comunicação dialógica (sem restrição ao direito de fala) e a ausência 
de coerção, representado pela autonomia e poder. O protagonista principal desse modelo é a sociedade civil organizada em conjunto com o Estado e o mercado (FERREIRA et al., 2011).

Essa relação do estado com a sociedade faz parte de uma tríade que é fundamental para a gestão democrática e é formada pelas dimensões econômico-financeira, institucional-administrativa e sociopolítica. As duas primeiras possuem predominância do modelo de administração pública gerencial, enquanto a Gestão Social predomina na última dimensão (PAULA, 2005).

A Gestão Social compõe a dimensão sociopolítica. Essa estrutura compreende os problemas oriundos do processo de interação estado e sociedade, envolvendo a gestão pública e a consciência do cidadão (PAULA, 2005). Nessa dimensão, além da Gestão Social, a Educação Fiscal surge como um método de ensinoaprendizagem que busca conscientizar o indivíduo dos seus direitos e deveres enquanto cidadão (PALMA, 2015).

Assim como a Gestão Social, a Educação Fiscal pode subsidiar o Estado e a própria sociedade de conhecimentos e fundamentos necessários para redimensionar suas políticas de natureza social. Esse entendimento resulta da compreensão da participação social na formulação e implantação de políticas, programas e projetos desenvolvidos pelo poder público (BORGES et al., 2008).

Nessa perspectiva, a educação fiscal é compreendida como prática educacional que busca desenvolver no cidadão competências, habilidades e atitudes necessárias ao pleno exercício da cidadania, no processo recíproco entre estado e sociedade (PALMA, 2015).

No Quadro 1, a partir das principais referências conceituais de Maia (2005) e Grzybovski et al. (2006), temos uma aproximação entre Gestão Social e Educação Fiscal como política pública com forte poder de transformação social no Brasil.

Quadro 1: Perspectivas teóricas da gestão social e educação fiscal trazidas por Maia (2005) e Grzybovski et al. (2006).

\begin{tabular}{|l|l|l|}
\hline \multirow{2}{*}{ Perspectivas } & Maia (2005) & Grzybovski et al. (2006) \\
\cline { 2 - 3 } $\begin{array}{l}\text { Origem no } \\
\text { Brasil }\end{array}$ & A partão Social & Educação Fiscal \\
\hline Influência & Americana e Europeia & A partir de 1969 \\
\hline Dimensão & Social, Política e Econômica & Europeia \\
\hline Valores & Democracia e cidadania & Econômica e Social \\
\hline Propósito & Viabilizar o desenvolvimento da sociedade & $\begin{array}{l}\text { Melhorar a relação entre o Estado e a Sociedade e a } \\
\text { conscientização do cidadão }\end{array}$ \\
\hline Agentes & $\begin{array}{l}\text { Atores em diversas instâncias do Estado, mercado } \\
\text { e sociedade civil. }\end{array}$ & Estado e Sociedade \\
\hline
\end{tabular}

Fonte: adaptado de Maia (2005) e Grzybovski et al. (2006)

Pode-se notar que o referencial teórico expressado no Quadro 1 mostra uma grande aproximação nas perspectivas da Gestão Social e Educação Fiscal. Os trabalhos foram publicados em período muito próximo, não havendo grande distinção entre os aspectos da influência, dimensão, valores, propósito e agentes que são trazidos por Maia (2005) e Grzybovski et al. (2006). Porém, evidencia-se uma disparidade contextual quando se analisa a perspectiva da Origem no Brasil que possuem períodos distintos.

Em sentido literal, a caracterização da Gestão Social tem como principais elementos: a tomada de decisão de forma coletiva, sem coerção e com liberdade para todos os envolvidos expressarem suas opiniões; 
a dialogicidade, sendo o diálogo expressado sobre a premissa da educação e da liberdade; a transparência, as informações e decisões precisam estar ao alcance de todos de forma clara e objetiva; e a emancipação, sendo materializado no pleno exercício da cidadania e no processo democrático (TENÓRIO, 1998).

De modo semelhante, a Educação Fiscal possui como características: o processo educacional, com foco no ensino e na aprendizagem de temas voltados ao exercício da cidadania; a consciência cívico-fiscal, que trabalha a função socioeconômica dos tributos como premissa para uma sociedade mais justa; a transparência, como instrumento de tornar público todas as informações de interesse da sociedade; e o controle social, sendo a expressão mais efetiva da participação popular na relação com o Estado (ZUAZU, 2016; BORGES et al., 2008; GRZYBOVSKI et al., 2006).

Em síntese, a gestão social e a educação fiscal no Brasil aproximam-se por possuírem essências e características em comum, que podem ser apresentadas como o enfoque social, tendo a cidadania, a transparência, a valorização do cidadão, o processo participativo e emancipação enquanto premissas finalísticas (TENÓRIO, 1998; MAIA, 2005; ZUAZU, 2016; BORGES et al., 2008; GRZYBOVSKI et al., 2006).

O intuito aqui é expor conceitos teóricos que despertem a reflexão e possibilitem um melhor entendimento de práticas que busquem a transformação social, por meio do pleno exercício da cidadania.

\section{CONCLUSÕES}

Neste artigo começamos por contextualizar os temas gestão social e educação fiscal, como caminhos para a construção da cidadania no Brasil. O referencial teórico inicial faz uma breve contextualização histórica acerca da origem do Estado brasileiro, algumas transformações e pontos em destaque que impulsionaram o debate desses temas no país.

Ao longo do artigo frisamos o processo de amadurecimento da relação estado com a sociedade. Nesse contexto, apresentamos como se formou a cultura política, social e cidadã na construção da cidadania no Brasil e alguns pontos da influência internacional que o país sofreu durante esse período de transformação política e social.

O referencial teórico final vai além da conceituação dos temas. Nessa parte, foram explorados conceitos, perspectivas e características da gestão social e da educação fiscal como políticas públicas que buscam a transformação social do país, por meio da consciência cidadã.

Uma análise mais profunda dos temas discutidos pode dar algumas pistas do que pode ser mais relevante para o amadurecimento do estado e da sociedade. Em estudos futuros seria interessante diagnosticar de forma detalhada o estado atual da gestão social e da educação fiscal no Brasil, podendo a investigação, eventualmente, ser realizada à luz dos principais atores envolvidos no processo de conscientização cidadã.

A exposição teórica demonstrou que os caminhos para a construção da cidadania no Brasil já possuem elementos importantes que estão enraizados, mesmo que de forma tímida, na cultura do país. A Gestão Social e a Educação Fiscal alimentam a esperança por dias melhores, na medida em que entendem a participação popular (cidadão) como a principal estratégia de transformação social. 
Por fim, entende-se que os temas discutidos não representam uma 'salvação' para o cenário político, social ou econômico do Brasil. É possível conceituá-los como estratégias ou modelos de gestão que, se trabalhados adequadamente, contribuirão significativamente para o desenvolvimento do país, porém sem descartar o surgimento de outras formas ou alternativas que tenham como finalidade a valorização da sociedade e do cidadão na relação estado e sociedade.

\section{REFERÊNCIAS}

BORGES, E. F.; PEREIRA, J. M.. Educação fiscal e eficiência pública: um estudo das suas relações a partir da gestão de recursos municipais. Revista de Educação e Pesquisa em Contabilidade, v.8, n.4, 2014. DOI:

https://doi.org/10.17524/repec.v8i4.1202

BORGES, E. F.; NASCIMENTO, V. C.; COSTA, F. M. S.; COSTA, G. M.. Uma visão exploratória da educação fiscal presente na formação do graduando em ciências contábeis da Universidade Federal do Rio Grande do Norte. Revista Brasileira de Contabilidade, Brasília, v.1, n.174, p.69-83, 2008.

BOURDIEU, P.. A economia das trocas simbólicas. 3 ed. São Paulo: Perspectiva, 1992.

BRASIL, O.; JUNIOR, D. L.. As reformas administrativas no Brasil: modelos, sucessos e fracassos. Revista do Serviço Público, p.5-32, 1998. DOI:

https://doi.org/10.21874/rsp.v49i2.364

BRESSER-PEREIRA, L.. Do Estado patrimonial ao gerencial. Letras, v.222, p.259, 2001.

BURKE, P.. Inevitáveis empréstimos culturais. São Paulo, 1997.

CANÇADO, A. C.; TENÓRIO, F. G.; PEREIRA, J. R.. Gestão social: reflexões teóricas e conceituais. Cadernos Ebape. $\mathbf{B r}$., v.9, n.3, p.681-703, 2011.

CARVALHO, J. J.. Imperialismo cultural hoje: uma questão silenciada. Revista USP, n.32, 1996-97, p.66-89, 1990.

COSTA, N. R.. Políticas públicas, justiça distributiva e inovação: saúde e saneamento na agenda social. São Paulo: Hucitec, 1998.

CUNHA, E. P.; CUNHA, E. S. M.. Políticas públicas sociais. In: CARVALHO, A.; SALLES, F., GUIMARÃES M.; UDE, W.. Políticas públicas. Belo Horizonte: UFMG, 2002. p.11-26.

D'ÁVILA, F. B.. L'immigration au Brésil. Rio de Janeiro: Agir, 1956.

DERANI, C.. Política Pública e a Norma Política. Revista da Faculdade de Direito UFPR, v.41, 2004. DOI: http://dx.doi.org/10.5380/rfdufpr.v41i0.38314

DRAIBE, S. M.; RIESCO, M.. Estados de Bem-Estar social e estratégias de desenvolvimento na América Latina. Um novo desenvolvimentismo em gestação? Sociologias, n.27, p.220254, 2011. DOI: http://dx.doi.org/10.1590/S151745222011000200009
ECHEVERRI, G.; ANDRADE, R.. Cultura cidadã: aproximação psicossocial da norma legal no contexto de uma favela carioca. Revista de Paz y Conflictos, Norteamérica, v.9, 2016.

FERREIRA, M. A. M.; EMMENDOERFER, M. L.; GAVA, R.. Administração pública, gestão social e economia solidária: avanços e desafios. Viçosa: UFV, 2011.

FORTES, A.; NEGRO, A.. Historiografia, trabalho e cidadania no Brasil. v.1, 2002

GRZYBOVSKI, D.; HAHN, T. G.. Educação fiscal: premissa para melhor percepção da questão tributária. Revista de Administração Pública, v.40, n.5, p.841-864, 2006. DoI: http://dx.doi.org/10.1590/S0034-76122006000500005

HUGON, P.. Demografia brasileira. São Paulo: Atlas, 1973.

MAIA, M.. Gestão social: reconhecendo e construindo referenciais. Revista Virtual Textos \& Contextos, v.4, n.4, 2005.

MOCKUS, A.; CORZO, J.. Dos caras de la convivencia: cumplir acuerdos y normas y no usar ni sufrir violência. Análisis Político, v.16, n.48, p.6-25, 2003.

MOTTA, R.. A história política e o conceito de cultura política. Revista de História, n.06, p.92-100, 1996.

OLIVEIRA, L. P.. O Brasil dos imigrantes. 2 ed. Rio de Janeiro: Jorge Zahar, 2002.

OLIVEN, R. G.. Violência e cultura no Brasil. Petrópolis, Vozes, 1989.

OLIVEN, R. G.. Cultura e Modernidade no Brasil. São Paulo em Perspectiva, v.15, n.2, p.3-12, 2001. DOI: http://dx.doi.org/10.1590/S0102-88392001000200002

PAULA, A. P. P.. Administração pública brasileira entre o gerencialismo e a gestão social. Revista de Administração de Empresas, v.45, n.1, p.3649, 2005. DOI: http://dx.doi.org/10.1590/S0034-75902005000100005

PALMA, C. C.. Para uma Política de Educação e Cidadania Fiscal em Portugal. Revista Contabilista, v.187, p.44-48, 2015.

PEREIRA, P. A. P.. Utopias desenvolvimentistas e política social no Brasil. Serviço Social \& Sociedade, n.112, p.729753, 2012. 
PEREIRA, D.; CRUZ, S. R.. Educação Fiscal: revisão da literatura. Estudos do ISCA, n.14, 2016. DOI:

https://doi.org/10.34624/ei.v0i14.4689

RODRIGUES, N.. Os africanos no Brasil. Rio de Janeiro: Nacional, 1945.

ROTHER, E. T.. Revisão sistemática X revisão narrativa. Acta paulista de enfermagem, v.20, n.2, p.5-6, 2007.

SADER, E.. Mercado contra democracia. In: Jornal do Brasil. Rio de Janeiro, 2004.

SCHOMMER, P. C.; NUNES, J. T.; MORAES, R. L..

Accountability, controle social e coprodução do bem público: a atuação de vinte observatórios sociais brasileiros voltados à cidadania e à educação fiscal. Publicações da Escola da AGU: Gestão Pública Democrática - Escola da Advocacia-
Geral da União Ministro Victor Nunes Leal, v.58, p.229-258, 2012.

TENÓRIO, F. G.. Gestão social: uma perspectiva conceitual. Revista de Administração Pública, v.32, n.5, p.7-23, 1998.

TENÓRIO, F. G.. (Re) visitando o conceito de gestão social. Desenvolvimento em questão, v.3, n.5, p.101-124, 2005. DOI: https://doi.org/10.21527/2237-6453.2005.5.101-124

VANNUCCHI, A.. Cultura Brasileira O que é, como se faz. 4 ed. São Paulo: Loyola, 2006.

VELHO, G.. A utopia urbana. Rio de Janeiro: Zahar, 1989.

ZUAZU, G. R. D. E.. La educación fiscal como herramienta de prevención del fraude fiscal. Revista Presupuesto y Gasto Público n.6, p.9-22, 2016.

A CBPC - Companhia Brasileira de Produção Científica (CNPJ: 11.221.422/0001-03) detém os direitos materiais desta publicação. Os direitos referem-se à publicação do trabalho em qualquer parte do mundo, incluindo os direitos às renovações, expansões e disseminações da contribuição, bem como outros direitos subsidiários. Todos os trabalhos publicados eletronicamente poderão posteriormente ser publicados em coletâneas impressas sob coordenação da Sustenere Publishing, da Companhia Brasileira de Produção Científica e seus parceiros autorizados. Os (as) autores (as) preservam os direitos autorais, mas não têm permissão para a publicação da contribuição em outro meio, impresso ou digital, em português ou em tradução. 